\title{
Gearing Up for Implementation: A New Children's Act for South Africa
}

\author{
Rose September and Mulugeta Dinbabo
}

\begin{abstract}
The South African Government is presently processing a new comprehensive Children's Act, which is expected to be promulgated in 2008. The primary purpose of the Act is to give effect to the rights of children as contained in section 28 of the Constitution as well as other international child rights instruments ratified by South Africa. The implementation of the new Act holds extensive implications for the targeted beneficiaries, the mandated implementers and the capacity of the relevant organisations. Drawing on the perceptions of 700 social workers who participated in a Children's Act orientation training programme, the authors draw attention to several implementation challenges needing to be addressed if the objectives of the new legislation are to be realised.
\end{abstract}

Keywords: Children's Act; policy implementation; social work training; South Africa

\section{Introduction and Background}

South Africa's post-apartheid government has prioritised children's well-being as a key development goal. This is evident in the fact that it has enshrined children's rights in its Constitution (1996) and ratified the UN Convention on the Rights of the Child (1989) in 1995 and the African Charter on the Rights and Welfare of the Child (1990) in 2000 along with a number of other international treaties such as the Hague Conventions on inter-country adoption and on inter-country abduction as well as the UN Protocol on Trafficking. In order to harmonise these commitments towards the realisation of child rights in domestic law, the govemment has introduced the new Children's Act (38 of 2005) (the Act), which is expected to be promulgated in 2008. It will replace existing legislation which originates in the apartheid period. The primary objectives as set out in Section 2 of the Act are to give effect to children's constitutional rights: to social services; to family and parental care or to alternative care when removed from the family 
environment; to protection from maltreatment, neglect, abuse and degradation and to the promotion of their best interests.

The Act also contains a number of key values and principles to set the ideological context and to guide the courts and decision-making professionals such as social workers, in interpreting the meaning of the different provisions of the Act. These are:

- to promote the preservation and strengthening of families;

- to strengthen and develop community structures to assist, provide care and protection to children;

- to protect children from discrimination, exploitation and physical, emotional or moral harm or hazards;

- to provide care and protection to children in need of care and protection, and to recognise the special needs that children with disabilities may have;

- generally, to promote the well-being of children.

One further key objective of note, which is the central focus of this paper, deals with the implementation mechanisms of the Act. Section 2(d) reads that the object of the Act is to: 'Make provision for structures, services and means for promoting and monitoring the sound physical, psychological, intellectual, emotional and social development of children'. Sections 4 and 5 of the Children's Act are significant in this regard, in that they go some way towards defining the issues of implementation.

In this article, the authors reflect on the perspectives of front-line socia workers about the challenges of implementing the new legislation. Over 1000 social workers attended a two-day Children's Act Orientation Training Programme commissioned by the Western Cape's Department of Social Development and presented by the University of Western Cape's Child and Youth Research and Training Programme in 2007. While the training was primarily intended for the Department's own staff, it also included social workers from non-governmenta organisations. The course evaluation questionnaire included an open-ended question about staff perceptions of the readiness of service organisations to implement the new Act. This article draws on the responses of the 700 socia workers who completed the questionnaire. Simple thematic analysis was used and three major categories emerged: organisational structures; human resources; and infrastructural capacity. The purpose here is to share the perspectives of social workers who will use the Act, in order to illustrate and suggest confirmation of the authors' own assessment of the challenges ahead.

\section{Implementing New Legislative Reforms}

Horwath (2006), in a paper delivered at a workshop with policy-makers in South Africa, draws on British experience to suggest some of the possible reasons why social policy implementation is inherently complex and challenging. She especially emphasised the fact that policy implementers generally underestimate how long it takes to develop policies - including the legislative process, which normally includes extensive consultation, of which the outcomes cannot always be predicted. Preparing for implementation involves extensive processes of planning and programming, which is fundamental to the success of implementation, yet seldom receives the attention it requires. Furthermore, the resource necessary to ensure the establishment of the infrastructural, institutional and human capacity required by organisations to implement new legislation, and how to secure them, is also generally not sufficiently recognised. In addition, the social welfare sector lacks adequate information systems that can provide the baseline data for planning, programming and sourcing of resources. On the basis of these lessons elements that should be considered for inclusion in a comprehensive implementation plan for the Children's Act (Barberton 2006 Horwath 2006; September 2006) are:

- strong, visible leadership closely associated with the vision of the Act:

- a coherent communication strategy reaching the beneficiaries as well as the implementers, based on a uniform understanding about the objectives of the Act;

- resource commitment in relation to the changes needed in the organisational capacity and the required values and behaviour of staff throughout the organisation;

prioritisation of essential services

- monitoring and evaluation, which are essential from the beginning of the planning and implementation process.

\section{Social Workers' Views on Implementation}

The Department of Social Development (DSD) is the custodian of the Act and therefore will be expected to take on the bulk of the responsibility for implementation. Considerable demands will be placed upon the child welfare service sector - a sector that has long been described as under-resourced and fragmented (September 2006) - and upon social work as a key profession within that sector. It is within this context that the DSD in the Western Cape commissioned the Child and Youth Research and Training Programme (CYRTP) at the University of the Western Cape to train social workers in the provisions of the new Act. On completion of training staff were asked to complete an evaluation that included an open-ended question about their expectations of implementation. The social workers' responses included a range of individual reflections, interpretations, perceptions and ideas about the implementation of the new legislation. Their responses, as presented below, were thematically analysed and clustered by the researchers into four main themes: the organisational design and structure; human resource capacity; institutional arrangements; and the infrastructure that is necessary to deliver the objectives of the new Act. 
Organisational Design and Intra-Organisational Relationships

Responses related to the design of the organisational structures in which the social workers operate can be subdivided into two main streams, one related to national and provincial competencies of the DSD and the other to the internal national and provincial competencies of the DSD and the other to the internal
organisational arrangements within the provincial department. A number of the respondents said they did not understand the division of national and provincial competencies, especially where the delivery of services is concerned. While the policy directives are clear, the way the national department often directs and demands action on the provincial level for national events and deliverables can be problematic as the provinces are already trying to deliver under the pressure of time and human resource constraints. Several respondents indicated that although there are improvements in the transformation of the Government's social development departments, these are not necessarily implemented successfully everywhere. The departments execute the work through district offices, and while this is perceived as a positive development, the social workers indicated that the interpretations and capacity to implement at district level are inconsistent.

It was clear that there was concern about the ability of departments to communicate, reinforce and monitor the organisational changes required to improve service delivery to those who do the work and need to be enabled to deliver in an appropriate manner. For example, several respondents identified their 'generic' responsibilities, covering all types of social work services, as making it extremely difficult for social workers to focus and grow their expertise in a specific field and to provide specialised services. Generic practice is seen as an organisational response to limited resources - with the needs of children and vulnerable families who require more comprehensive and intensive work being valnerable

With regard to the tension between the lack of resources and servicing clients, there seemed to be some ambivalence about restructuring the service deliven mechanisms and structures in the DSD. A number of respondents called for the establishment of a dedicated Children's Directorate within the DSD in order to facilitate integrated comprehensive service planning, delivery and capacity development. Respondents also indicated that too many changes happened too frequently because there is a perceived lack of substantive long-term vision. They were of the view that any re-structuring should be based on thorough research and planning and should be accompanied by clear and comprehensive communication about the rationale, objectives and processes to be followed. Several respondents also stated that many of the people in management positions are not social workers or social welfare policy experts and as a result there seems to be lack of understanding about the purpose and methods of social development and the role of social workers.

The government's social welfare services and those delivered by the nongovernmental service providers are closely linked. Government's role sustaining these organisations through adequate financial and institutional arrangements is critical for the sector. A number of social workers mentioned that there is some tension between the two sectors that must be resolved before the Act places even more demands on the non-governmental organisations (NGOs). One of the examples mentioned was that the loss of social work staff affects NGOs disproportionately because they can only afford to pay salaries that are far below government salaries (September 2007).

The new Children's Act seems to be requiring both a specialised child protective service that will respond to the serious cases of intentional harm and neglect and a flexible and accessible organisational structure that will enable clients to access a range of integrated services with dependable and accountable service providers (September 2006). This means that the purpose and functions of service units of organisations must be explicitly defined and their policies procedures and goals clearly stated. The design of the organisation must also facilitate the improvement of the working conditions of the staff. In this regard, improvement in working conditions for social workers requires attention in order to reduce case loads (which at present can be over 200) and provide flexible work schedules, better supervision, access to management and an increased number of support staff. As Mack (2001) has pointed out, reducing case loads cannot be achieved without new staff and that requires making the job of social workers more attractive.

\section{Human Resources}

All the respondents noted the problem of a lack of human resources. The respondents indicated that the demand for social workers is presently greater than the existing numbers of professionals and the number of trained professionals is not keeping up with the demand. Recurring themes included the high case loads and the low salaries that are disproportionate to the volumes of work expected from social workers and the demoralising effect that this situation has on the workforce. There is a national retention strategy in place, which is aimed at keeping social workers in the system and providing incentives for new recruits (DSD 2004). This includes improved salaries, internal promotions and bursaries for prospective social work students. A number of respondents stated that there is an immediate need to diversify the provision of social services to include more social auxiliary workers, child and youth care workers and volunteers. There must, however, be clear definitions and job descriptions to ensure clear professional boundaries.

The need for further training and capacity building of social workers was identified by respondents as a barrier to their development. They indicated that most of them never had in-service training; neither were they very happy with the quality of their supervision. These factors will impact even more as they are expected to develop their capacity to implement the new Act. The new Act comes with an expectation that staff who work directly with children and families and those who supervise and manage this work are knowledgeable, confident and 
able to exercise professional judgement. Most of the respondents also mentioned that the current legislative change will place additional burdens on social workers in terms of time and add substantially to their already heavy case loads. They also mentioned the importance of working very closely with the other relevant departments such as health and education to give effect to the objectives of the Act. This requires more joint training and the development of integrated service plans. To accomplish this, continued professional development and specialised training was suggested.

\section{Institutional Arrangements and Procedural Guidelines}

Many respondents noted that the task of formulating the regulations and establishing the administrative, procedural and institutional arrangements to implement the Children's Act needs to be a priority of the DSD. Respondents also mentioned that the DSD must develop the regulations and design special instruments such as rules, procedures, functions and operational steps that would ensure the effective and efficient implementation of the Act throughout the entire system. In addition, all the old practice guidelines and regulations must be revised in line with the new Act According to several informants, the instruments and rules are crucial to translating the general mandate of the law into a set of practice requirements for the DSD workers. These are needed to guide them in their practice and relationships with service beneficiaries. Many respondents mentioned mandatory training in child welfare practice including the new Act. There was also a suggestion to institute disciplinary measures or sanctions for non-compliance.

These statements indicated the social workers' desire for more explicit written and standardised policy guidelines to direct their interventions. They seemed to believe that such policy guidelines would greatly facilitate uniformity among the implementers and supervisors. With regard to formalised and sustained supervision, which was seen as a central means of underpinning the e instituted for the purposes of case interventions, monitoring and staff development.

Infrastructure

Suggestions and comments were wide ranging with regard to infrastructural changes that would be needed in order to implement the Children's Act. The suggestions did not only pertain to the DSD, but also to other departments and non-governmental organisations. However, many respondents emphasised the central role of the DSD in the provision of adequate infrastructural support for the Act. Most of the participants commented that the current infrastructural facilities are not sufficient to fully implement the Act. They listed the following facilities that are needed: office buildings, drop-in centres, secure care facilities, places of safety, children's homes, reform schools, equipment and vehicles. It is a lack of office equipment such as telephones and computers and many offices do not have enough vehicles. They felt that these and other related resources should be put in place before the Act is promulgated. According to most respondents, the courts are not all childfriendly and must be upgraded to acceptable standards, especially with regard to the quality of facilities and special arrangements for Children's Court procedures. The particular needs of child victims of sexual abuse were also noted in light of the Government's new Sexual Offences Act and public campaigning on this issue.

\section{Managing the Change Process}

It is clear from the survey of the Western Cape's social workers that much of what Horwath (2006) drew attention to from the British experience has direct implications for the implementation of the Children Act. In particular the importance of ensuring that the organisational aspects, infrastructure and resources that are in place have to be appreciated - especially the human resources. To help ensure this happens, Horwath emphasised that that implementation of new legislation should be steered by a Strategic Implementation Plan. While the DSD must take the lead on this, the NGO sector and other government departments need to participate in the development of such a strategy, which should place emphasis on managing the change as a process rather than focusing solely on the content of the Act Special attention should be paid to capacity building and organisational support for staff. The human factor is the single most important determinant of success in the implementation of social welfare programmes. Horwath suggests that there must always be the right mix of professional competence coupled with a supportive work environment. In the case of social workers, the latter should include opportunities for continual learning and development, and high-quality supervision, moral support and administrative support systems. And all of this comes at a price.

The South African parliament now requires that implementation of the proposed legislation must be costed and presented to parliament for consideration with the proposed legislation. Consultants were commissioned by the DSD to conduct the costing of the Children's Act. The aim of the costing was to assist the national parliament and the provincial legislatures to plan and ensure that budgets are in place in the coming years to meet the care and protection needs and rights of children. The report indicated that the government's current budget is failing to meet the care and protection needs of children in the country and that there are huge discrepancies between provinces in the provision of socia welfare services. This is without even giving consideration to the additional costs associated with implementing the new Act (Barberton 2006). 
The most significant challenge for the implementation of the legislation identified in the report on costing is the fact that there are too few social workers in the country. The report indicates that about 8656 social workers and 7682 auxiliary social workers were needed in 2005/2006 to meet needs at a basic level of supply. These figures will increase to 16,504 for social workers and 14,648 for auxiliary social workers in 2010/11. But for full coverage (high scenario), 47,305 social workers and 34,158 auxiliary social workers were needed in 2005/06 and for $2010 / 11$ the estimates are 66,329 and 48,660 social workers and auxiliary social workers respectively (Barberton 2006). It must also be recognised that the costing was based on information received from the provincial and local service providers who in turn relied on very poor information systems and data sources.

The issues around the quality of the data become more complex given the diversity and variations in the type and scope of services at local levels. Collecting and using information to plan the delivery of social services is at the heart of evaluation and monitoring and consequently new innovative interventions. The successful implementation of the Act will require the design and implementation of proper monitoring and evaluation tools for effective and systematic assessments, efficiency, impact and sustainability of key operations (Anderson 1997). Effective information systems are therefore an essential investment that must be at the core of fiscal planning for the implementation of the new Act.

All these issues are not simply technical problems or even purely an issue of money. Political championship is imperative for successful implementation of social policy reform and the Children's Act is no exception. Visible leadership and the active participation of a political authority such as a minister with whom the public can associate the policy are essential to strengthen its status and sustainability. Political leadership is not limited to party politics, important as that is particularly in a country where one party, the ANC, commands such overwhelming support and authority. Attention also needs to be given to patterns of power and influence between and within organisations.

\section{Conclusion}

Child welfare services in South Africa constitute the bulk of the work currently delivered by the both government and non-government social welfare service providers, with social work at the core of that workforce. The system has historically responded to the needs of a range of vulnerable children and their families by providing access to basic means of survival, and child protection services. The new Children's Act by contrast will provide a legislative framework comprehensive in its reach, capable of pulling together the fragmented parts of the broader social welfare services network to serve vulnerable children and their families more holistically. But to achieve these ideals, the biggest challenge that the DSD faces is to enhance its own capacity and influence on the broader political powers, which will be essential to bring about the infrastructural and institutional changes necessary to implement the Act.

The new Act provides an important window of opportunity to transform child welfare services within the context of the South African Government's broader social development strategies (Patel 2005). This means acknowledging that old ways of doing things may not be the best. The changes and resources required are not for providing more of the same but for building the capacity to structure child welfare interventions in such a way as to reflect international best practices and establish indigenous evidence-based models. In this regard, well-designed knowledge development processes and demonstration projects in which social work will play an important role are important contributors. Implementation of the Act must be conceived as a multi-dimensional process with crucial linkages across programmes and projects provided by a connected network of dependable government departments and civil society organisations functioning as an open system of highly interdependent inputs and outcomes. The planning for implementing the Children's Act requires strong political leadership and decision-makers that can guide the crucial processes of identifying and assessing needs, constructing new service delivery mechanisms, carefully integrating the clusters of programmes, coordinating their activities and appropriating adequate resources. All of this is needed to support social workers and other front-line practitioners who ultimately are the ones to turn legislation into lived reality for children and their families.

\section{References}

African Charter on the Rights and Welfare of the Child. 1990. OAU Doc CAB/LEG/24.9/49 (entered into force 29 November 1999). Anderson, J. 1997. Public poficymoking: an introduction (2nd edn). Boston: Houghton

Mifflin. Barberton, C. 2006. The cost of the Children's Bill: Estimates of the cost to

government of

the services envisaged by the comprehensive Children's Bill for the period 2005 to 2010 Cornerstone Economic Research. Children's Act. 2005. Republic of South Africa

Children's Act no 38 of 2005. Cape Town:

CREDA Communications. Department of Social Development. 2004. Retention strategy. Unpublished document.

Pretoria: Department of Social Development. Horwath, J. 2006. From legislation to

implementation: Making the Children's Act work for

children, families \& the workforce. Paper presented at the seminar for the Western Cape Department of Social Development, Senior Government and NGO Managers, 13 August.

Mack, K. 2001. Working around a crisis. Children's Voice 10(5): 20-22. Maser, C. 1997. Sustainable community development, principles and concepts. Boca

Raton, FL: St Lucie Press. Patel, L 2005. Social welfare ft social development in South Africa. Cape Town: Oxford

University Press Southern Africa. South African Constitution. 1996. Constitution of the Republic of South Africa, 1996 (Act

No 108 of 1993). Pretoria: Government Printing. 
September, R. 2006. The progress of child protection in South Africa. International Journal of Social Welfare 15(1): S65-S72. September, R. L. 2007. Separating social welfare services and social welfare grants:

challenges and opportunities. Maatskaplike Werk/Social Work 43(2): 93-105. United Nations. 1989. United Nations Convention on the Rights of the Child. UN General Assembly Document A/RES/44/25. New York: UN.

Rose September is a Professor in the Faculty of Community and Health Sciences at the University of the Western Cape, South Africa. She heads the Child and Youth Research and Training Programme. She researches and teaches in developmental social welfare with a specialist interest in child welfare and child protection and the utilisation of research as an instrument for transformation - social change and social justice. She is currently seconded to UNICEF as the Head of their Cape Town sub-office. Mulugeta Dinbabo is a researcher in Social Development at the Child and Youth Research and Training Programme, University of the Western Cape, South Africa. He is also studying for a doctorate at UWC. Correspondence to Professor Rose September, Child 8t Youth Research and Training, Faculty of Community Health and Sciences, Private Bag X17, Bellville 7535, South Africa, email: rseptember@uwc.ac.za 